\title{
Management of Germ Cell Tumours of the Testis in Adult Patients. German Clinical Practice Guideline Part I: Epidemiology, Classification, Diagnosis, Prognosis, Fertility Preservation, and Treatment Recommendations for Localized Stages
}

\author{
Sabine Kliesch ${ }^{a}$ Stefanie Schmidt ${ }^{b}$ Doris Wilborn ${ }^{b}$ Clemens Aigner ${ }^{c}$ Walter Albrecht ${ }^{d}$ \\ Jens Bedke ${ }^{\mathrm{e}}$ Matthias Beintker ${ }^{f}$ Dirk Beyersdorffg ${ }^{\text {Carsten Bokemeyer }}{ }^{\mathrm{h}}$ Jonas Busch ${ }^{\mathrm{i}}$ \\ Johannes Classen ${ }^{j}$ Maike de Wit ${ }^{k}$ Klaus-Peter Dieckmann' Thorsten Diemer ${ }^{m}$ Anette Dieing ${ }^{n}$ \\ Matthias Gockel $^{0}$ Bernt Göckel-Beining ${ }^{p}$ Oliver W. Hakenberg ${ }^{q}$ Axel Heidenreich ${ }^{r}$ \\ Julia Heinzelbecker ${ }^{s}$ Kathleen Herkommer ${ }^{t}$ Thomas Hermanns ${ }^{u}$ Sascha Kaufmann ${ }^{v}$ \\ Marko Kornmann $^{w}$ Jörg Kotzerke ${ }^{\mathrm{x}}$ Susanne Krege ${ }^{\mathrm{y}} \quad$ Glen Kristiansen $^{\mathrm{z}}$ Anja Lorch ${ }^{\mathrm{A}}$ \\ Arndt-Christian Müller $^{v}$ Karin Oechsle $^{\text {h }}$ Timur Ohloff $^{B} \quad$ Christoph Oing $^{\text {h }}$ Ulrich Otto $^{C}$ \\ David Pfister $^{r}$ Renate Pichler $^{\mathrm{D}}$ Heinrich Recken ${ }^{\mathrm{E}}$ Oliver Rick ${ }^{\mathrm{F}} \quad$ Yvonne Rudolph $^{\mathrm{G}}$ \\ Christian Ruf $^{\mathrm{H}}$ Joachim Schirren' Hans SchmelzJ Heinz Schmidberger ${ }^{\mathrm{K}}$ Mark Schrader $^{\mathrm{L}}$ \\ Stefan Schweyer $^{\mathrm{M}}$ Stefanie Seeling ${ }^{\mathrm{N}}$ Rainer Souchon $^{\mathrm{V}}$ Christian Winter $^{\mathrm{O}}$ Christian Wittekind $^{\mathrm{P}}$ \\ Friedemann Zengerling $^{\mathrm{Q}}$ Dirk-Henrik Zermann ${ }^{\mathrm{R}}$ Roger Zillmann ${ }^{\mathrm{S}}$ Peter Albers ${ }^{\mathrm{A}}$ \\ ${ }^{a}$ Centre of Reproductive Medicine and Andrology, Department of Clinical and Surgical Andrology, University Hospital

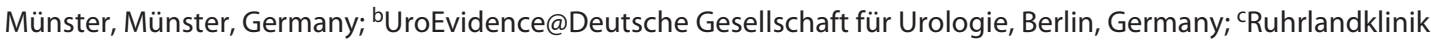

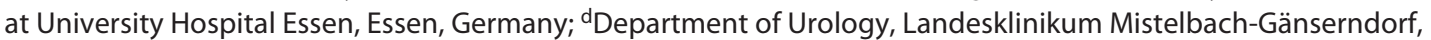

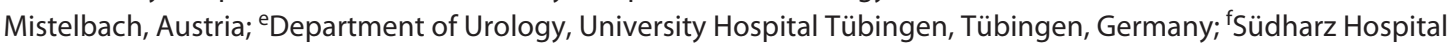 \\ Nordhausen gGmbH, Nordhausen, Germany; ${ }^{9}$ Clinic and Polyclinic for Diagnostic and Interventional Radiology and

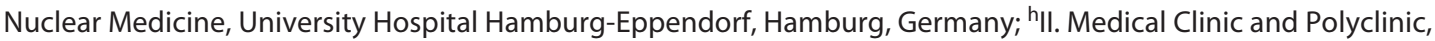 \\ University Hospital Hamburg-Eppendorf, Hamburg, Germany; 'Department of Urology, Charité University Hospital, \\ Berlin, Germany; 'Department of Radiotherapy, Radiological Oncology and Palliative Medicine, St. Vincentius- \\ Kliniken, Karlsruhe, Germany; ${ }^{k}$ Clinic for Internal Medicine - Hematology, Oncology and Palliative Medicine, Vivantes \\ Clinic Neukölln, Berlin, Germany; 'Department of Urology, Asklepios Klinik Altona, Hamburg, Germany; ${ }^{\mathrm{m} C l i n i c}$ and \\ Polyclinic for Urology, Pediatric Urology and Andrology, University Hospital Gießen, Gießen, Germany; ${ }^{\text {nClinic for }}$ \\ Internal Medicine - Hematology and Oncology, Vivantes Clinics Am Urban, Berlin, Germany; ${ }^{\circ}$ HELIOS Clinics Berlin-

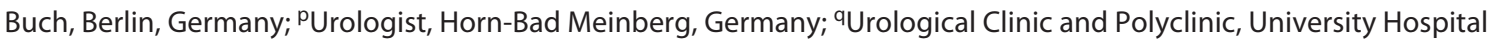 \\ Rostock, Rostock, Germany; ' 'Department of Urology, University Hospital Cologne, Cologne, Germany; ${ }^{\text {sDepartment }}$ \\ of Urology, University Hospital Saarland, Saarbrücken, Germany; ${ }^{t}$ Urological Clinic and Polyclinic of the Technical \\ University of Munich, Munich, Germany; "Department of Urology, University Hospital Zurich, University of Zurich, \\ Zurich, Switzerland; 'vepartment for Radiooncology, University Hospital Tübingen, Tübingen, Germany; ${ }^{\text {w} C l i n i c ~}$ \\ for General and Visceral Surgery, University Hospital UIm, Ulm, Germany; ${ }^{{ }^{K} K l i n i k}$ und Poliklinik für Nuklearmedizin, \\ University Hospital Dresden, Dresden, Germany; ${ }^{{ } K E M}$, Protestant Hospital Essen-Mitte, Clinic for Urology, Pediatric

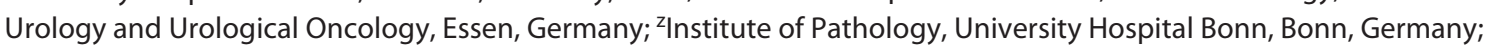

S. Kliesch and S. Schmidt contributed equally to this study and should be considered co-first authors.

karger@karger.com www.karger.com/uin Karger $\stackrel{\text { ' }}{5}$ BOPEN ACCESS
(C) 2021 The Author(s)

Published by S. Karger AG, Basel

This is an Open Access article licensed under the Creative Commons Attribution-NonCommercial-4.0 International License (CC BY-NC) (http://www.karger.com/Services/OpenAccessLicense), applicable to the online version of the article only. Usage and distribution for commercial purposes requires written permission.
Sabine Kliesch

Centrum für Reproduktionsmedizin und Andrologie, Abteilung für Klinische und Operative Andrologie, Universitätsklinikum Münster

Albert-Schweitzer-Straße 33, DE-48149 Münster (Germany)

kliesch@ukmuenster.de 
ADepartment of Urology, University Hospital Düsseldorf, Düsseldorf, Germany; ${ }^{B}$ Advisor, German Foundation for Young Adults with Cancer, Berlin, Germany; 'Urological Competence Centre for Rehabilitation, Bad Wildungen, Germany; DDepartment of Urology, Medical University Innsbruck, Innsbruck, Austria; EHFH, Hamburger FernHochschule Studienzentrum Essen (Distance Learning University, Essen Study Centre), Essen, Germany; ${ }^{{ }^{F} \text { Klinik }}$ Reinhardshöhe GmbH, Bad Wildungen, Germany; ${ }^{G}$ German Cancer Society, Berlin, Germany; ${ }^{H}$ Department of Urology, Bundeswehrkrankenhaus (German Federal Armed Forces Hospital), Ulm, Germany; 'Helios Clinics, Wiesbaden, Germany; 'Department of Urology, Bundeswehrkrankenhaus (German Federal Armed Forces Hospital), Koblenz, Germany; ${ }^{\mathrm{K} C l i n i c}$ and Polyclinic for Radiooncology and Radiotherapy, University Hospital Mainz, Mainz,

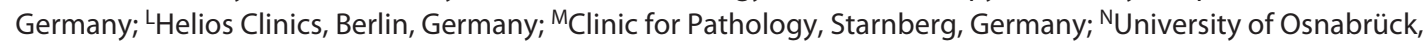

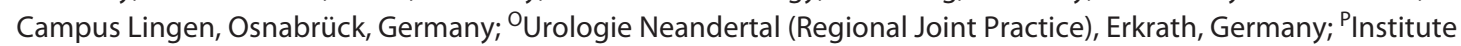
of Pathology, University Hospital Leipzig, Leipzig, Germany; ${ }^{\circledR}$ Department of Urology, University Hospital Ulm, Ulm,

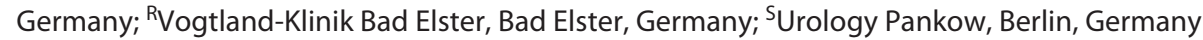

\section{Keywords}

Germ cell tumour of the testis · Diagnosis · Prognosis .

Staging $\cdot$ Fertility preservation $\cdot$ Clinical practice guideline

\begin{abstract}
Introduction: This is the first German evidence- and consensus-based clinical guideline on diagnosis, treatment, and follow-up on germ cell tumours (GCTs) of the testis in adult patients. We present the guideline content in two publications. Part I covers the topic's background, methods, epidemiology, classification systems, diagnostics, prognosis, and treatment recommendations for the localized stages. Methods: An interdisciplinary panel of 42 experts including 1 patient representative developed the guideline content. Clinical recommendations and statements were based on scientific evidence and expert consensus. For this purpose, evidence tables for several review questions, which were based on systematic literature searches (last search was in March 2018) were provided. Thirty-one experts entitled to vote, rated the final clinical recommendations and statements. Results: We provide 161 clinical recommendations and statements. We present information on the quality of cancer care and epidemiology and give recommendations for staging and classification as well as for diagnostic procedures. The diagnostic recommendations encompass measures for assessing the primary tumour as well as procedures for the detection of metastases. One chapter addresses prognostic factors. In part I, we separately present the treatment recommendations for germ cell neoplasia in situ, and the organ-confined stages (clinical stage I) of both seminoma and nonseminoma. Conclusion: Although GCT is a rare tumour entity with excellent survival rates for the localized stages, its management requires an interdisciplinary approach, including several clin-
\end{abstract}

ical experts. Quality of care is highly related to institutional expertise and can be reassured by established online-based second-opinion boards. There are very few studies on diagnostics with good level of evidence. Treatment of metastatic GCTs must be tailored to the risk according to the International Germ Cell Cancer Collaboration Group classification after careful diagnostic evaluation. An interdisciplinary approach as well as the referral of selected patients to centres with proven experience can help achieve favourable clinical outcomes.

(c) 2021 The Author(s)

Published by S. Karger AG, Basel

\section{Background}

The incidence of germ cell tumours (GCTs) of the testis is low with about 10 out of every 100,000 men in Germany per year [1]. However, the importance arises from the fact that GCTs represent the most common type of cancer in men aged $20-40$ years, with $25 \%$ of all malignancies diagnosed in this age group [1]. Survival rates are excellent for the localized stages (95-100\%) and are still good for the metastasized stages (70-90\%) [2]. Clinically, GCTs are classified into seminomas (about 60\%) and non-seminomatous GCTs $[1,3]$.

For all stages, the tumour-specific therapeutic success depends on the correct diagnosis and staging, which is essential to avoid under- but also overtreatment. Interdisciplinary cooperation between urologists, oncologists, radio-oncologists, radiologists, and pathologists is mandatory, especially for multidisciplinary therapy control in the metastatic poor prognosis and relapsed patient groups. In addition, established online-based secondopinion boards enable urologists and oncologists to reassure especially first-line treatment decisions [4-6]. 
So far, no official evidence-based German clinical practice guideline on this topic has been available. There are interdisciplinary consensus recommendations $[7,8]$, which were developed by the interdisciplinary German Testicular Cancer Study Group (GTCSG) of the German Cancer Society. However, they are mainly based on expert consensus and do not follow the transparent and high-quality methodology development criteria set up by the Association of Scientific Medical Societies in Germany (AWMF) [9].

Therefore, the German Society of Urology (DGU) together with the interdisciplinary GTCSG initiated the development of an S3 German-language clinical practice guideline on this topic. The guideline category S3 refers to a German guideline classification system in which S3 represents the highest methodological standard. It involves both evidence- and consensus-based concepts to achieve highest quality guideline recommendations from an interdisciplinary panel group [10].

The German S3 guideline is freely available for download in both short and long versions: https://www.awmf. org/leitlinien/detail/11/043-049OL.html. A separate method report on the guideline development process is additionally available.

Physicians and other medical service providers who are involved in the diagnostics, treatment, and follow-up of GCTs (all stages, outpatient and inpatient care as well as rehabilitation) are the target audience of the present guideline. A patient guideline for patients and lay persons will be published soon. The guideline also comprises quality indicators for measuring the implementation of the guideline recommendations in routine clinical care; these data will be presented in a future publication.

We present the English translation of the main content of this guideline in two separate parts, which includes all clinical recommendations and statements of the original guideline. Part I relates to epidemiology, classification systems, diagnostics, prognosis, and treatment recommendations for the localized stages. Part II covers the treatment recommendations for the metastatic stages as well as relapsed and refractory disease, follow-up schedules, toxicity management, quality of life, and palliative and supportive care.

\section{Objective}

The overall aim of the present project is to improve the treatment of GCT and thus increase survival of the patients afflicted with the disease. Also, quality of life of sur-

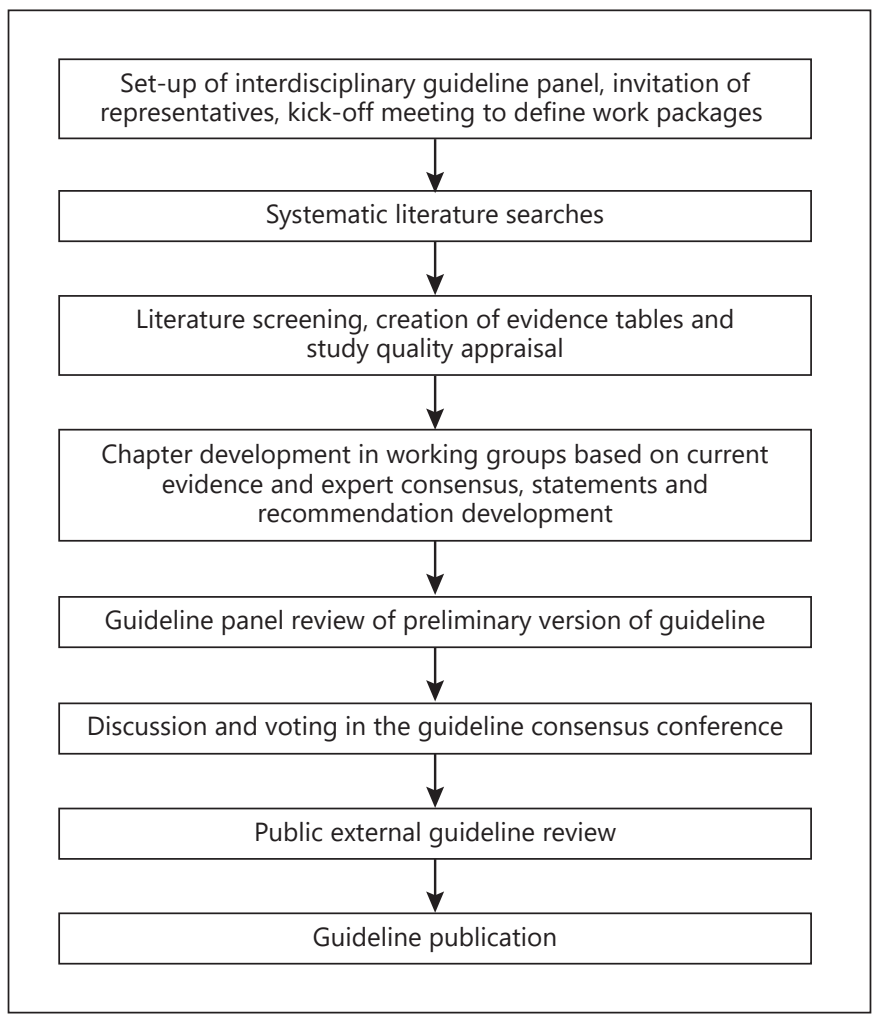

Fig. 1. Steps of the guideline development process.

viving patients is intended to be improved by efforts to minimize acute and late toxicity of treatment.

For these goals, we aimed at developing the first German guideline for the management of GCTs in adult patients that is explicitly based on formal scientific evidence and if required on consensus in a working group of dedicated experts.

\section{Methods}

In the guideline development process, we followed the AWMF methodology for S3 guidelines [10]. This process is illustrated in Figure 1. For details, see the German method report (available at: https://www.awmf.org/leitlinien/detail/ll/043-049OL.html).

\section{Members and Funding}

The interdisciplinary panel for this guideline consisted of 32 experts (including a patient representative) entitled to vote, as well as several external experts and working group leaders (see Table 1). The project was funded by the German Cancer Aid. Methodological supervision was provided by the German Guideline Program in Oncology [11]. Conflicts of interest were disclosed by all guideline panel members and are available in the guideline report (http://www.awmf.org/leitlinien/detail/ll/043-044.html). 
Table 1. Coordinators, medical societies, and organizations involved

Coordinator

Scientific Team (DGU) (not entitled to vote)
Guideline office

Prof. Dr. Sabine Kliesch, DGU (deputy: Prof. Dr. Peter Albers, GTCSG) Janine Weiberg (DGU)

Prof. Dr. Jens Bedke

Prof. Dr. Jonas Busch

PD Dr. Julia Heinzelbecker

Prof. Dr. David Pfister

PD Dr. Christian Ruf

Dr. Stefanie Schmidt

Dr. Doris Wilborn

Dr. Christian Winter

PD Dr. Friedemann Zengerling

\section{Medical society or organization}

German Society of Urology (DGU)

German Society of Radiation Oncology (DEGRO)

German Society of Andrology (DGA)

German Society for General and Visceral Surgery (DGAV)

German Society of Hematology and Medical Oncology (DGHO)

German Society for Nuclear Medicine (DGN)

German Association for Palliative Medicine (DGP)

German Society of Pathology (DGP)

German Society of Nursing Science (DGP)

German Society for Thoracic Surgery (DGT)

German Society of Radiology (DRG)

Association of German Urologists (BvDU)

Association of German Pathologists (BVP)

Austrian Society of Urology and Andrology (ÖGU)

Swiss Society of Urology (SGU)

Pain and Supportive Therapy, Quality of Life, and Palliative Care Working

Group (Arbeitskreis Schmerztherapie, Supportivtherapie, Lebensqualität, und

Palliativmedizin)

Oncology Working Group (AKO)

Supportive Measures in Oncology, Rehabilitation, and Social Medicine Working Group (ASORS)

Internal Oncology Working Group (AIO)

Andrology Working Group (AKA)

Urological and Nephrological Diseases Rehabilitation Working Group (AKR)

Oncological Pathology Working Group (AOP)

Oncologic Thoracic Surgery Working Group (AOT)

Palliative Care Working Group (APM)

Radiooncology Working Group (ARO)

Tumor Classification in Oncology Working Group (ATO)
Participants in guideline development

Prof. Dr. Susanne Krege (deputy: Prof. Dr. Sabine Kliesch)

Prof. Dr. Johannes Claßen (deputy: Prof. Dr. Rainer Souchon)

Prof. Dr. Hans Schmelz (deputy: PD Dr. Kathleen Herkommer)

Prof. Dr. Marko Kornmann

Prof. Dr. Anja Lorch (deputy: Dr. Christoph Oing)

Prof. Dr. Jörg Kotzerke

Dr. Matthias Gockel

Prof. Dr. Stefan Schweyer (deputy: Prof. Dr. Glen Kristiansen)

Heinrich Recken, B.A. (deputy: Prof. Dr. Stefanie Seeling)

Prof. Dr. Clemens Aigner

PD Dr. Dirk Beyersdorff (deputy: Prof. Dr. Sascha Kaufmann)

Dr. med. Bernt Göckel-Beining (deputy: Dipl. Med. Roger Zillmann)

Prof. Dr. Glen Kristiansen (deputy: Prof. Dr. Stefan Schweyer)

PD Dr. Walter Albrecht (deputy: Dr. Renate Pichler)

PD Dr. Thomas Hermanns

Dr. Matthias Beintker (deputy: Prof. Dr. Oliver Hakenberg)

Prof. Dr. Oliver Hakenberg

Prof. Dr. Oliver Rick (deputy: Prof. Dr. Maike de Wit)

Prof. Dr. Carsten Bokemeyer (deputy: Dr. Annette Dieng)

PD Dr. Diemer (deputy: PD Dr. Kathleen Herkommer)

Prof. Dr. Ullrich Otto (deputy: Prof. Dr. Dirk-Henrik Zermann)

Prof. Dr. Christian Wittekind

Prof. Dr. Joachim Schirren

Prof. Dr. Karin Oechsle

Prof. Dr. Heinz Schmidberger (deputy: PD Dr. Arndt-Christian Müller)

Prof. Dr. Christian Wittekind 
Table 1 (continued)

Urological Oncology Working Group (AUO) Prof. Dr. Mark Schrader (deputy: Prof. Dr. Axel Heidenreich)

GTCSG (Hodentumorgruppe der Deutschen Krebsgesellschaft)

Prof. Dr. Klaus Peter Dieckmann (deputy: PD Dr. Christian Ruf)

PRiO (Arbeitsgemeinschaft Prävention und integrative Medizin in der

Onkologie)

German Foundation for Young Adults with Cancer (Deutsche Stiftung für

junge Erwachsene mit Krebs)

External experts

Dr. Ivonne Rudolph

Timur Ohloff, M.Phil.

Prof. Axel Heyll (MDK Competence Center Oncology)

Dr. Klaus Kraywinkel (Robert Koch Institute)

Dr. Ekkehard Ost (MDK Competence Center Oncology)

DGU, Deutsche Gesellschaft für Urologie; DEGRO, Deutsche Gesellschaft für Radioonkologie; DGA, Deutsche Gesellschaft für Andrologie; DGAV, Deutsche Gesellschaft für Allgemein und Viszeralchirurgie; DGHO, Deutsche Gesellschaft für Hämatologie und Onkologie; DGN, Deutsche Gesellschaft für Nuklearmedizin; DGP, Deutsche Gesellschaft für Palliativmedizin; DGP, Deutsche Gesellschaft für Pathologie; DGP, Deutsche Gesellschaft für Pflegewissenschaften; DGT, Deutsche Gesellschaft für Thoraxchirurgie; DRG, Deutsche Röntgengesellschaft; BvDU, Berufsverband der Deutschen Urologen; BVP, Berufsverband Deutscher Pathologen; ÖGU, Österreichische Gesellschaft für Urologie und Andrologie; SGU, Schweizerische Gesellschaft für Urologie; AKO, Arbeitskreis Onkologie; ASORS, Arbeitsgemeinschaft Supportive Maßnahmen in der Onkologie, Rehabilitation, und Sozialmedizin; AIO, Arbeitsgemeinschaft Internistische Onkologie; AKA, Arbeitskreis Andrologie; AKR, Arbeitskreis Rehabilitation urologische \& nephrologische Erkrankungen; AOP, Arbeitsgemeinschaft Onkologische Pathologie; AOT, Arbeitsgemeinschaft Onkologische Thoraxchirurgie; APM, Arbeitsgemeinschaft Palliativmedizin; ARO, Arbeitsgemeinschaft Radiologische Onkologie; ATO, Arbeitsgemeinschaft Tumorklassifikation in der Onkologie; AUO, Arbeitsgemeinschaft Urologische Onkologie; GTCSG, German Testicular Cancer Study Group; PRiO, Prevention and Integrative Medicine in Oncology Working Group.

Evidence and Recommendation Development

In January 2017, the scope of work and the work packages were defined during the first consensus conference held in Berlin, Germany. Seventy-two key questions were defined, and afterwards several systematic literature searches were conducted using the databases Medline (via Ovid) and the Cochrane Library. The search period was from January 2010 to May 2017. A search update was performed in March 2018. Cohort studies, clinical trials, systematic reviews, meta-analyses, and international clinical guidelines were considered. We only included publications in English and German. Case reports, case series, case-control studies, editorials, commentaries, conference abstracts, and studies available in other languages were excluded.

For all studies included, relevant information was extracted in evidence tables, and the risk of bias was assessed according to study design, using AGREE [12], AMSTAR [13], the Cochrane tool for RCTs [14], SIGN [15], Quadas [16], and Quips [17]. The Oxford criteria were used for the level of evidence ratings [18] (Table 2). For the therapeutic key questions, the quality of the evidence was rated according to the Grading of Recommendations, Assessment, Development, and Evaluation (GRADE) approach [19].

The final evidence- and consensus-based recommendations and statements were elaborated, and a formal consensus of the guideline panel was achieved applying the nominal group technique under the guidance of an external moderator. The second and concluding consensus conference was held in Berlin in May 2018. E-references are listed in the online supplementary eReferences file (see www.karger.com/doi/10.1159/000510407 for all online suppl. material).

The following wordings were used for characterizing the strength of the clinical recommendations (see also Table 2):

- A: strong recommendation: "we recommend" or "is recommended/is not recommended"

- B: weak recommendation: "should/should not"

- 0: inconclusive recommendation: "can"

\section{Results}

Chapter 3: Quality of Care

See also Table 3.

1 We recommend that patients with a metastatic GCT belonging to the poor prognosis group according to the International Germ Cell Cancer Collaboration Group (IGCCCG) are treated at centres with proven experience (GRADE of recommendation A, level of evidence $2 b$ ) $[4,6]$.

2 We recommend that GCT patients with post-chemotherapeutic residual tumours receive residual tumour resection only after multidisciplinary consultation at centres with proven experience, which fulfil the prerequisites for multidisciplinary surgical interventions (expert consensus).

\section{Chapter 4: Epidemiology, Risk Factors, Screening, and Prevention}

1 In men aged 20-44 years, GCT is the most common malignant disease, accounting for about $25 \%$ of all cancers (statement, 2b) [1].

2 Within the last decades, the incidence of GCT has increased to currently 10 out of every 100,000 men per year in all industrialized countries including Germany (raw disease rate) (statement, 2b) [1].

3 GCTs are among the cancers with highest survival rates. The patient's prognosis essentially depends on tumour histology, clinical stage, age, and quality of care (statement, 2b) $[1,6]$. 
Table 2. Levels of evidence according to the Oxford Centre for Evidence-Based Medicine 2009 classification system (from [18])

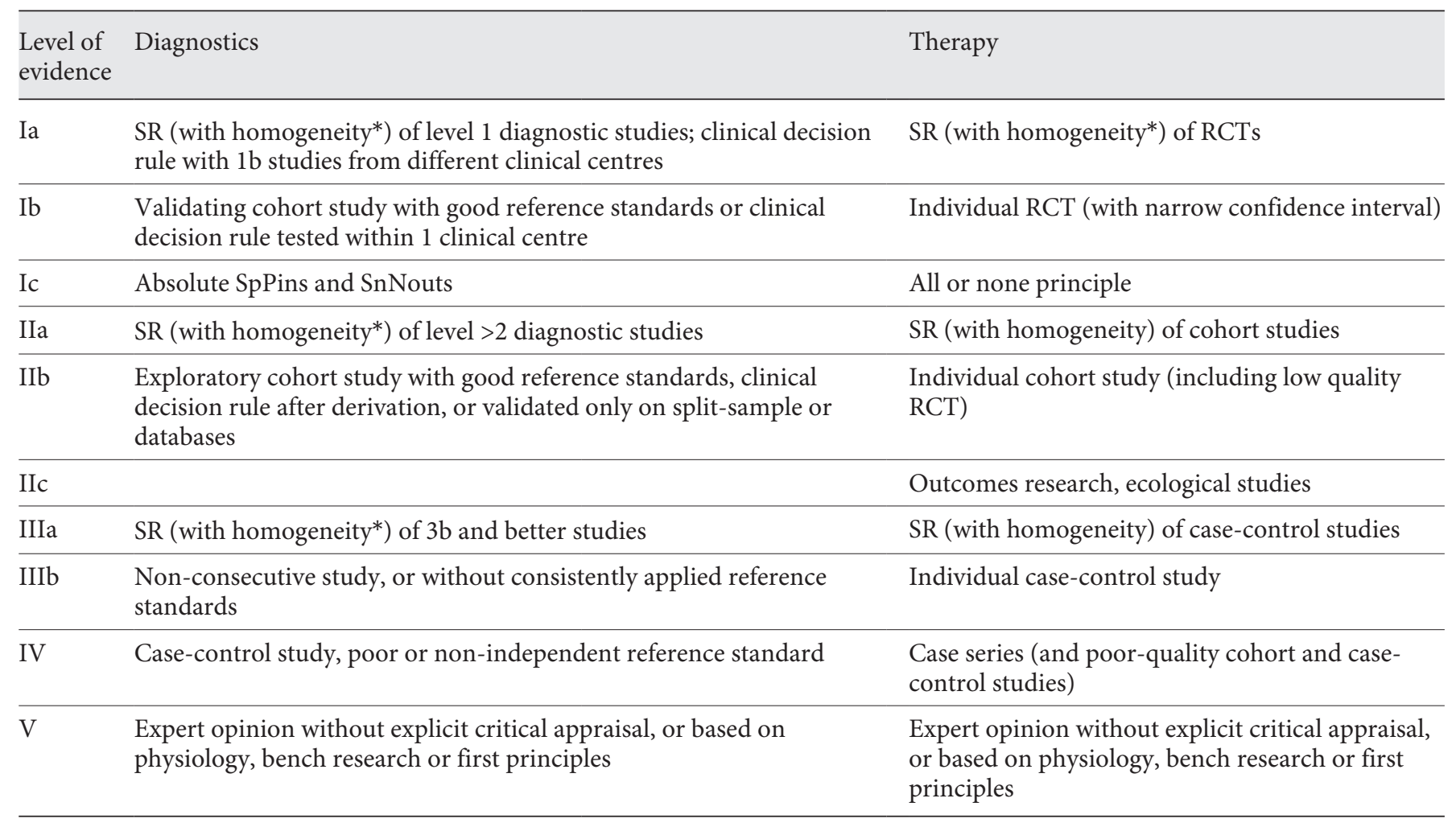

RCT, randomized control trial; SR, systematic review. * By homogeneity, we mean a systematic review that is free of worrisome variations (heterogeneity) in the directions and degrees of results between individual studies. Not all systematic reviews with statistically significant heterogeneity need be worrisome, and not all worrisome heterogeneity need be statistically significant.

4 Accepted pathogenetic risk factors for the development of GCTs are previous contralateral GCT, history of maldescensus testis, positive family history, and male infertility (statement, 2b) [e20-e25].

5 General screening for the presence of a GCT is not recommended $(A, 5)$ [e26-e28].

6 Regular self-examination of the testicles should be recommended especially to young men, as it can lead to early diagnosis (expert consensus).

7 In the presence of risk factors, the possibility of a GCT should be investigated (expert consensus).

\section{Chapter 5: Pathological Classification}

1 We recommend the 2016 WHO classification for the histopathological evaluation of GCTs [e29] (expert consensus).

\section{Chapter 6: Diagnostics, Stages, and Classification} Systems

See also Tables 3 and 4.
Imaging procedures in the context of local diagnostics and/or staging diagnostics:

1 On clinical suspicion of a GCT, we recommend to perform a physical examination as well as a bilateral testicular ultrasonography conducted with a high-resolution transducer involving at least $7.5 \mathrm{MHz}$ (expert consensus).

2 We recommend that men with newly diagnosed GCT receive a contrast-enhanced computed tomography (CT) scan of the abdomen/pelvis and chest for staging $(A, 5)[\mathrm{e} 30, \mathrm{e} 31]$.

3 In patients with newly diagnosed GCT and contraindications to iodine-containing contrast media, such as allergy, impaired renal function, or thyroid dysfunction, MRI of the abdomen/pelvis is recommended to replace a CT $(A, 5)[\mathrm{e} 30]$. In case of the abovementioned contraindications, a non-contrast-enhanced CT scan of the chest should be performed additionally to investigate pulmonary involvement $(B, 5)$. 
Table 3. Prognostic classification of metastatic GCT [2]

Good prognosis group

Non-seminomatous

GCT (56\% of cases)

\begin{tabular}{ll} 
GCT $(56 \%$ of cases $)$ & Testis/retroperitoneal primary \\
& No non-pulmonary visceral metastases \\
& AFP $<1,000 \mathrm{ng} / \mathrm{mL}$ \\
& hCG $<5,000 \mathrm{IU} / \mathrm{L}(1,000 \mathrm{ng} / \mathrm{mL})$ \\
& LDH $<1.5 \times$ ULN \\
\hline Seminoma & All of the following: \\
(90\% of cases) & Any primary site \\
& No non-pulmonary visceral metastases \\
& Normal AFP \\
& Any hCG \\
& Any LDH
\end{tabular}

Intermediate prognosis group

Non-seminomatous Testis/retroperitoneal primary

GCT (28\% of cases) No non-pulmonary visceral metastases

Any of the following:

AFP $\geq 1,000$ and $\leq 10,000 \mathrm{ng} / \mathrm{mL}$ or

hCG $\geq 5,000$ and $\leq 50,000$ IU/L or

$\mathrm{LDH} \geq 1.5$ and $\leq 10 \times \mathrm{ULN}$

\begin{tabular}{ll}
\hline Seminoma & All of the following: \\
(10\% of cases) & Any primary site \\
& Non-pulmonary visceral metastases \\
& Normal AFP \\
& Any hCG \\
& Any LDH \\
\hline
\end{tabular}

Poor prognosis group

Non-seminomatous

GCT (16\% of cases)

\begin{abstract}
(At least) one of the following:
Mediastinal primary

Non-pulmonary visceral metastases

AFP $>10,000 \mathrm{ng} / \mathrm{mL}$ or

hCG $>50,000 \mathrm{IU} / \mathrm{L}(10,000 \mathrm{ng} / \mathrm{mL})$ or

$\mathrm{LDH}>10 \times \mathrm{ULN}$
\end{abstract}

Seminoma No patients classified as poor prognosis

IGCCCG, International Germ Cell Cancer Collaboration Group; GCT, germ cell tumour; AFP, $\alpha$-fetoprotein; hCG, human chorionic gonadotropin; LDH, lactate dehydrogenase; ULN, upper limit of normal. ${ }^{\text {a }}$ For the staging, the serum tumour markers determined immediately prior to the start of chemotherapy (same day) are relevant.

4 Patients of the IGCCCG poor prognosis group as well as patients with excessive beta human chorionic gonadotropin ( $\beta$-hCG) values, multiple pulmonary metastases, or neurological symptoms should receive an additional cranial MRI $(B, 5)$ [e28].

5 An FDG-PET/CT is not recommended for routine use in primary staging diagnostics $(A, 1 a)$ [e32].

6 FDG-PET/CT can be considered in seminoma patients with residual tumours larger than $3 \mathrm{~cm}$ in diam-
Table 4. Recommended examinations for primary staging

\begin{tabular}{|c|c|}
\hline Test & Patients \\
\hline Physical examination & All patients \\
\hline Ultrasonography of the testes & All patients \\
\hline $\begin{array}{l}\text { Serum tumour markers } \\
\text { AFP } \\
\beta \text {-hCG } \\
\text { LDH }\end{array}$ & All patients \\
\hline Chest/abdominal/pelvic CT & All patients \\
\hline Cranial MRI & $\begin{array}{l}\text { Symptomatic patients and } \\
\text { patients in the IGCCCG } \\
\text { poor prognosis group, or } \\
\text { patients with multiple } \\
\text { pulmonary metastases and/ } \\
\text { or high } \beta \text {-hCG values } \\
(>5,000 \mathrm{IU} / \mathrm{L})\end{array}$ \\
\hline $\begin{array}{l}\text { Further diagnostics } \\
\text { Fertility tests } \\
\text { Sperm analysis/cryopreservation } \\
\text { Testosterone } \\
\text { LH } \\
\text { FSH }\end{array}$ & $\begin{array}{l}\text { Patients with unfinished } \\
\text { family planning, active or } \\
\text { postponed desire for } \\
\text { offspring as well as for } \\
\text { ruling out/detecting } \\
\text { hypogonadism }\end{array}$ \\
\hline
\end{tabular}

AFP, a-fetoprotein; hCG, human chorionic gonadotropin; $\mathrm{LDH}$, lactate dehydrogenase; CT, computed tomography; IGCCCG, International Germ Cell Cancer Collaboration Group; $\mathrm{LH}$, luteinizing hormone; FSH, follicle-stimulating hormone. We recommend advising all patients on the cryopreservation of sperm preferably before the primary surgical intervention and, if necessary, arrange consultation with an andrologist or a fertility centre.

eter and with normal or normalized serum tumour markers after therapy completion $(0,1 a)$ [e32]. The $\mathrm{CT}$ as part of the FDG-PET/CT examination should preferably be performed as contrast-enhanced CT (expert consensus).

7 Timing of FDG-PET/CT for the assessment of serum tumour marker-negative residual tumours in patients with seminoma is at the earliest recommended at 6 weeks after the end of the last cycle of chemotherapy (expert consensus).

8 FDG-PET/CT is not recommended in patients with a non-seminomatous GCT (expert consensus).

Serum tumour markers (primary diagnostics and staging diagnostics):

9 We recommend determination of the serum tumour markers $\alpha$-fetoprotein (AFP), $\beta$-hCG, and lactate de- 
hydrogenase in patients with suspected GCT prior to orchiectomy (expert consensus).

10 In patients with preoperatively elevated serum tumour marker levels, we recommend to monitor AFP, $\beta$-hCG, and lactate dehydrogenase postoperatively every $5-7$ days until normal values or nadir is reached, or until serum tumour markers increase (expert consensus).

Surgically determined diagnosis/inguinal exploration of the testis (including organ preservation):

11 If a GCT is suspected, we recommend inguinal testicular exploration and, in case of evidence for a malignancy, radical orchiectomy of the respective testis is recommended $(A, 5)[\mathrm{e} 28, \mathrm{e} 33]$.

12 In the presence of a healthy contralateral testis, organpreserving excision is not recommended in case of a unilateral malignant GCT (with the exception of a teratoma without accompanying germ cell neoplasia in situ [GCNIS]) (expert consensus).

13 Organ-preserving tumour excision is recommended in patients with a bilateral GCT, with monorchid tumour, in case of stromal or other benign tumours (epidermoid cyst and monodermal teratoma), respectively (expert consensus).

Organ-preserving tumour resection in GCT:

14 For eradication of GCNIS after organ-preserving surgery in monorchid tumour patients, we recommend adjuvant radiation of the affected testis with $18-20 \mathrm{~Gy}$. As the development of a solid GCT from GCNIS may take several years, we recommend the discussion of regular sonographic controls with patients who declined radiotherapy for the purpose of paternity and to those who are under surveillance (expert consensus).

15 We recommend that patients with increased risk for contralateral GCNIS undergo contralateral biopsy at the time of orchiectomy after appropriate counselling $(A, 4)$ [e34].

Pathological examination of the testicular tissue (including GCNIS):

16 For patients with ultrasonographic testicular microlithiasis and no other risk factors, testicular biopsy is not recommended $(A, 2 a)$. A testicular biopsy can be considered in patients with microlithiasis presenting one of the following additional parameters: infertility, previous tumour disease of the testicle, first-degree relative with GCT, history of maldescended testis, or testicular atrophy with a sonographic testis volume $<12$ $\mathrm{mL}(0)[\mathrm{e} 35]$.

$17 \mathrm{We}$ recommend that the pathohistological report on the testicular specimen includes the following information: labelling of side, testicular size, maximum tumour size (in 3 dimensions), macroscopic features of the epididymis, spermatic cord and tunica vaginalis, tumour in the surgical margins (yes/no), histological subtype with specification of individual components and percentage according to WHO 2016, tumoral venous and/or lymphatic invasion (yes/no), invasion of the tunica albuginea (yes/no), rete testis (yes/no), soft tissue of the hilum (yes/no) and the epididymis or spermatic cord (yes/no), GCNIS in non-tumorous parenchyma (yes/no), and pT category according to the 2017 TNM classification (expert consensus).

Fertility and cryopreservation of spermatozoa:

18 GCT therapy impairs the patients' fertility to a variable extent, depending on the treatment regimen applied and the initial situation (statement, expert consensus).

19 We recommend that if a GCT is suspected, cryopreservation of spermatozoa is offered to the patient before treatment initiation (before orchiectomy, at the latest before chemotherapy or radiotherapy) $(A, 5)$ [e28, e36].

$20 \mathrm{We}$ recommend that patients with azoospermia at the time of scheduled cryopreservation prior to therapy are offered bilateral testicular sperm extraction (if possible simultaneously with orchiectomy) $(A, 5)[\mathrm{e} 36]$.

Staging diagnostics and classification:

21 To characterize the anatomical spread of the GCT, we recommend the use of the current TNM classification (expert consensus).

\section{Chapter 7: Prognosis}

1 The stage-independent 5-year survival rate in patients with GCT (in Germany) is $97.9 \%$ for seminoma and 94.9\% for non-seminomatous GCT (statement, $2 b$ ) [1].

2 For stage I GCT patients, the cancer-specific 10-year survival rate is $99.7 \%$ and the 10 -year overall survival rate is $95-99 \%$ (statement, $2 b$ ) [e37].

3 The 5-year survival rates for metastatic GCT are 86$95 \%$ for patients in the good prognosis group, $72-85 \%$ for the intermediate prognosis group, and $48-64 \%$ for the poor prognosis group (statement, $2 b$ ) [2, e38].

4 In non-seminomatous GCTs, lymphovascular invasion represents the only prospective multivariate analysis-validated risk factor for recurrence in clinical stage I (cSI) disease (statement, 2b). In seminoma, tumour size correlates positively with the occurrence of recurrences in patients with cSI disease. Data on the impact of stromal rete testis infiltration are inconsistent. With a tumour size of less than $4 \mathrm{~cm}$ and a lack of stromal rete testis infiltration, the risk of recurrence is minimal $(<5 \%)$ (statement, 1b) [e39-e46]. 
Table 5. Recurrence rates in studies with non-seminomatous GCT patients in cSI [26-31]

\begin{tabular}{lrlll}
\hline Reference & $N$ & Therapy & $\begin{array}{l}\text { Recurrence } \\
\text { rate, } \%\end{array}$ & $\begin{array}{l}\text { Mean follow-up, } \\
\text { months }\end{array}$ \\
\hline$[26]$ & 43 & $2 \times$ PEB & 2.5 & 42 \\
{$[27]$} & 114 & $2 \times \mathrm{PEB}$ & 1.7 & 48 \\
{$[28]$} & 42 & $2 \times \mathrm{PEB}$ & 4.8 & 79 \\
{$[29]$} & 58 & $2 \times \mathrm{PEB}$ & 1.7 & 93 \\
{$[30]$} & 40 & $2 \times \mathrm{PEB}$ & - & 113.2 \\
{$[31]$} & 142 & $2 \times \mathrm{PEB}$ & 0.7 & 79 \\
\hline
\end{tabular}

GCT, germ cell tumour; cSI, clinical stage I.

5 We recommend the classification of metastatic GCT to be based on the prognostic criteria of the IGCCCG (expert consensus).

\section{Chapter 8: Primary and First-Line Therapy}

Here, in part I, we outline the primary surgical treatment of the testis and the treatment of the localized stages. Part II of the publication will summarize all advanced disease stages.

\section{Inguinal Exposure}

In case of a testicular suspicious mass, the surgical inguinal exposure of the testis constitutes both diagnostics and therapy. Depending on the initial findings, it is performed with or without frozen section-based intraoperative assessment of the dignity of the tumour for either an organ-preserving approach (enucleation) or complete removal of the testis (orchiectomy), including the spermatic cord. In life-threatening disease due to metastatic spread, orchiectomy can be postponed and performed later in the course of the disease.

Rare giant tumours with a diameter of more than 10 $\mathrm{cm}$ are an exception. In these cases, an inguino-scrotal approach including resection of the respective scrotal skin area should be applied [e47].

There are no data available that would justify scrotal orchiectomy as an exclusion criterion for a subsequent surveillance strategy. Cryopreservation of sperm should be performed before taking the first therapeutic step, which usually is orchiectomy (see above).

The insertion of a silicone implant during orchiectomy procedure should be discussed with and offered to the patient. This is not associated with an increased risk of infection. The overall surgical complication rate is about 7\% [e48]. The satisfaction rates (assessed by structured
Table 6. Recurrence rates of chemotherapy versus surveillance in studies with non-seminomatous GCT patients in cSI [22-24, 32, 33]

\begin{tabular}{|c|c|c|c|}
\hline Reference & $N$ & Therapy & $\begin{array}{l}\text { Recurrence } \\
\text { rate, } \%\end{array}$ \\
\hline \multirow[t]{2}{*}[22]{} & 234 & Surveillance & 30.0 \\
\hline & 148 & $1-2 \times$ PEB & $4.0(6.5+3.6)$ \\
\hline \multirow[t]{2}{*}{ [23] } & 231 & $2 \times \operatorname{PEB}(\mathrm{hr})$ & 0.8 \\
\hline & 358 & surveillance (lr) & 19.0 \\
\hline \multirow[t]{3}{*}{ [32] } & 60 & $2 \times \mathrm{CVB}(\mathrm{hr})$ & 1.6 \\
\hline & 124 & surveillance/ & 12.9 \\
\hline & 40 & $1 \times$ CVB (lr) & 10.0 \\
\hline \multirow[t]{2}{*}{ [33] } & 258 & $1 \times \mathrm{PEB}(\mathrm{hr})$ & 3.1 \\
\hline & 255 & $1 \times \mathrm{PEB} /$ surveillance $(\mathrm{lr})$ & 1.6 \\
\hline \multirow[t]{2}{*}{ [24] } & 167 & $2 \times \operatorname{PEB}(\mathrm{hr})$ & 1.2 \\
\hline & 287 & surveillance (lr) & 16.7 \\
\hline
\end{tabular}
risk.

GCT, germ cell tumour; cSI, clinical stage I; hr, high risk; lr, low

patient interviews) exceed $80 \%$ among these patients [e49, e50].

\section{Therapy of GCNIS}

1 In monorchid GCNIS, local radiotherapy with 18-20 Gy attains eradication of GCNIS cells in more than $95 \%$ of cases (statement, 2b) [e53, e54].

2 In case of active surveillance of GCNIS, an invasive GCT develops within 5 years in $50 \%$ of cases (statement, expert consensus).

3 In case of unilateral GCNIS in the presence of a healthy contralateral testis, either orchiectomy or sonographic follow-up (active surveillance) are recommended (expert consensus).

4 In case of bilateral GCNIS, both testes should be irradiated (expert consensus).

5 After adjuvant chemotherapy, more than $50 \%$ of GCNIS cases develop into a manifest tumour. Additional radiotherapy should be performed $(B, 2 b)[e 54$, e55].

6 Radiotherapy of GCNIS-affected testes causes sterility. Prior cryopreservation of sperm (from the ejaculate or in the presence of azoospermia by means of a testicular sperm extraction) is recommended to be discussed with the patient (expert consensus).

7 After local radiotherapy with 18-20 Gy, long-term hypogonadism can arise in $30 \%$ of cases. Regular controls 
Table 7. Recurrence rates of RLA versus surveillance or chemotherapy in studies with non-seminomatous GCT patients in cSI $[25,34]$

\begin{tabular}{lrll}
\hline Reference & $N$ & Therapy & Recurrence rate, \% \\
\hline$[25]$ & 191 & RLA & 7.8 \\
& 191 & $1 \times$ PEB & 1.0 \\
\hline$[34]$ & 54 & Surveillance & 10.2 \\
& 27 & RLA & 13.0 \\
\hline
\end{tabular}

GCT, germ cell tumour; cSI, clinical stage I.

of the serum testosterone level are recommended $(A$, 2b) [e53, e54].

8 Three or more cycles of cisplatin-based chemotherapy lead to eradication of GCNIS in $60-70 \%$ of cases. A control biopsy should be performed before radiotherapy or, if the subsequent procedure depends on the result, 2 years after chemotherapy at the earliest $(B, 2 b)$ [e54, e55].

Seminoma in non-metastatic cSI:

9 In seminoma, the tumour size correlates positively with the presence of occult metastases in cSI. Data on stromal rete testis infiltration are inconsistent. With a tumour size of $<4 \mathrm{~cm}$ and absence of rete testis infiltration, the risk of occult metastases is minimal $(<5 \%)$ (statement, 2a) [e46].

10 All treatment options (active surveillance, adjuvant chemotherapy with carboplatin, and adjuvant radiotherapy) achieve the same survival rates with stageadapted treatment of the disease in case of recurrence (statement, GRADE: very low quality of evidence) [e56e63].

11 Age, comorbidities, patient preferences, and patient compliance are recommended to be considered for the choice of therapy (expert consensus).

12 Patients with seminoma and cSI are recommended to be followed up by active surveillance and in case of recurrence, they are treated according to stage-specific guidelines ( $A, G R A D E$ : very low quality of evidence) [e57, e59, e60, e64-e67].

13 In patients with a tumour diameter $>4 \mathrm{~cm}$, adjuvant therapy can be considered in individual cases, especially if compliance concerns or psychological distress of the patient are suspected. One to 2 cycles of carboplatin (dosed according to AUC 7) or, alternatively, radiotherapy of the para-aortic region with 20 Gy are options for adjuvant therapy. Both therapeutic modal-
Table 8. Recurrence rates in studies with non-seminomatous GCT patients in cSI managed with surveillance before 1992 and after $1993[20,21,35]$

\begin{tabular}{llll}
\hline Reference & $N$ & Therapy & Recurrence rate, \% \\
\hline$[35]$ & 371 (total) & & 28.0 \\
& $157(1988-1992)$ & $\mathrm{lr}$ & 18.7 \\
& & $\mathrm{hr}$ & 54.5 \\
\hline$[35]$ & $214(1993-2005)$ & $\mathrm{hr}$ & 14.2 \\
& & $\mathrm{hr}$ & 49.2 \\
\hline$[21]$ & 1,226 (total) & & 30.6 \\
& & $\mathrm{lr}$ & 12.0 \\
& & $\mathrm{hr}$ & 50.0 \\
\hline$[20]$ & 1,139 (total) & & 19.0 \\
\hline
\end{tabular}
risk.

GCT, germ cell tumour; cSI, clinical stage I; hr, high risk; lr, low

ities offer specific advantages and disadvantages, which are recommended to be discussed in detail with the patient $(0,2 b)$ [e63, e68].

Non-seminomatous GCT in non-metastatic cSI:

14 The lymphovascular invasion of tumour cells in the primary tumour is the most important risk factor for occult retroperitoneal metastases. In the low-risk situation (without lymphovascular invasion), the risk of occult metastases is about 15\%, and in the high-risk situation (with lymphovascular invasion), it is up to $50 \%$ (statement, 2b) [e37, e39-e44, e45, e69].

15 In the low-risk situation, active surveillance is recommended $(A, 2 b)$ [e70-e72].

16 In the high-risk situation, the treatment modalities including 1 cycle of PEB versus active surveillance should be discussed with the patient. One cycle of PEB reduces the risk of recurrence from 50 to $3 \%$. The overall survival of both groups is the same. In case of individual patient's reluctance to surveillance and adjuvant chemotherapy, or in case of contraindications against chemotherapy, primary nerve-sparing retroperitoneal lymph node dissection with modified field boundaries should be considered alternatively. It is recommended to perform this intervention at centres with proven experience ( $B, G R A D E$ : moderate quality of the evidence) [e72-e74].

See Tables 5-8 for the corresponding recurrences rates. Stage I disease with serum tumour marker increase:

17 In patients with persistently elevated serum tumour markers after orchiectomy (cSI), it is recommended to 
rule out non-GCT-related causes for serum tumour marker elevation (expert consensus).

18 Patients with persistent tumour marker elevations after orchiectomy and negative imaging, in whom other causes for serum tumour marker elevation have been ruled out, should be closely monitored prior to treatment decision-making until either an unequivocal continuous marker increase of AFP or $\beta$-hCG becomes evident or a detectable lesion upon imaging becomes evident (expert consensus).

\section{Key Messages of Part I}

- GCTs have an incidence of 10:100,000 men/year but represent $25 \%$ of cancer cases diagnosed in the age group of 20-40 years.

- The patient's prognosis essentially depends on tumour histology, clinical stage, age, and quality of care.

- Stage I GCTs have excellent 5-year survival rates with $97.9 \%$ for seminoma and $94.9 \%$ for non-seminomatous GCT.

- Five-year survival rates for metastatic GCTs are $86-95 \%$ in the good prognosis group, $72-85 \%$ for the intermediate prognosis group, and $48-64 \%$ for the poor prognosis group.

- We recommend the 2016 WHO classification for histopathological evaluation of GCTs.

- We recommend the classification of metastatic GCTs based on the prognosis criteria of the IGCCCG classification.

- The patients' fertility is impaired by GCT therapy to variable extent, depending on the treatment modality and the initial situation. Therefore, we recommend that cryopreservation of spermatozoa is offered to the patient before any treatment.

- FDG PET/CT is not recommended for routine use in primary staging.

- In monorchid GCNIS, local radiotherapy with 18-20 Gy eradicates GCNIS cells in more than $95 \%$ of cases.

- CNIS develop invasive cancer. In these cases, additional radiotherapy should be performed.

- In seminoma cSI, all treatment options (active surveillance, adjuvant chemotherapy with carboplatin, and adjuvant radiotherapy) achieve the same survival rates.

- Patients with seminoma cSI are recommended to be followed up by active surveillance and treated stage-adapted in the case of recurrence.
- In patients with non-seminomatous GCT, active surveillance is recommended in the low-risk situation.

- In patients with high-risk non-seminomatous GCT, 1 cycle of PEB reduces the risk of recurrence from 50 to $3 \%$. The overall survival of both treatment options, 1 cycle of PEB versus surveillance, is the same.

\section{Acknowledgements}

The German Guideline Program in Oncology of the Association of the Medical Scientific Societies (AWMF), the German Cancer Society (DKG), and German Cancer Aid (DKH) supervised this project and gave methodological support. Administrative support by Ingrid Rambow (Münster) is greatly appreciated. Uwe Hölzel (Dresden) also participated in this project.

\section{Conflict of Interest Statement}

The evaluation of conflicts of interest showed only minor relevance on the topic and can be obtained upon request.

\section{Funding Sources}

German Cancer Aid Foundation (DKH) (Reference No. 70112789).

\section{Author Contributions}

All authors have made substantial contributions to the conception or design of the work or the acquisition, analysis, or interpretation of data for the work and on drafting the work or revising it critically for important intellectual content; have approved the final version to be published; and have agreed to be accountable for all aspects of the work in ensuring that questions related to the accuracy or integrity of any part of the work are appropriately investigated and resolved.

\section{References}

1 Bertz J, Buttmann-Schweiger N, Kraywinkel K. Epidemiologie bösartiger Hodentumoren in Deutschland. Der Onkologe. 2017;23(2): 90-6.

2 IGCCCG. International germ cell consensus classification: a prognostic factor-based staging system for metastatic germ cell cancers. International germ cell cancer collaborative group. J Clin Oncol. 1997 Feb;15(2): 594-603.

3 Ruf CG, Isbarn H, Wagner W, Fisch M, Matthies C, Dieckmann KP. Changes in epidemio- logic features of testicular germ cell cancer: age at diagnosis and relative frequency of seminoma are constantly and significantly increasing. Urol Oncol. 2014 Jan;32(1):33.

4 Collette L, Sylvester RJ, Stenning SP, Fossa $\mathrm{SD}$, Mead GM, de Wit R, et al. Impact of the treating institution on survival of patients with "poor-prognosis" metastatic nonseminoma. European organization for research and treatment of cancer genito-urinary tract cancer collaborative group and the medical research council testicular cancer working party. J Natl Cancer Inst. 1999 May 19;91(10): 839-46.

5 Zengerling F, Krege S, Schrader AJ, Schrader M. [National second opinion network for testicular cancer patients - transferring guidelines into practice!]. Aktuelle Urol. 2014 Nov; 45(6):454-6.

6 Albany C, Adra N, Snavely AC, Cary C, Masterson TA, Foster RS, et al. Multidisciplinary clinic approach improves overall survival outcomes of patients with metastatic germ-cell tumors. Ann Oncol. 2018 Feb 1;29(2):341-6. 
7 Krege S, Beyer J, Souchon R, Albers P, Albrecht W, Algaba F, et al. European consensus conference on diagnosis and treatment of germ cell cancer: a report of the second meeting of the European germ cell cancer consensus group (EGCCCG): part I. Eur Urol. 2008 Mar;53(3):478-96.

8 Krege S, Beyer J, Souchon R, Albers P, Albrecht W, Algaba F, et al. European consensus conference on diagnosis and treatment of germ cell cancer: a report of the second meeting of the European germ cell cancer consensus group (EGCCCG): part II. Eur Urol. 2008 Mar;53(3):497-513.

9 AWMF. AWMF-Regelwerk "Leitlinien." 1. Auflage 2012 [Internet]. 2016 December 16. Arbeitsgemeinschaft der Wissenschaftlichen Medizinischen Fachgesellschaften (AWMF) Ständige Kommission Leitlinien. Available from: https://www.awmf.org/fileadmin/ user_upload/Leitlinien/AWMF-Regelwerk/ AWMF-Guidance_2013.pdf.

10 AWMF. AWMF-Regelwerk "Leitlinien." 1. Auflage 2012. Arbeitsgemeinschaft der Wissenschaftlichen Medizinischen Fachgesellschaften (AWMF)- Ständige Kommission Leitlinien; 2012.

11 GGPO. German guideline program in oncology [Internet]. 2020 Mar 27. Available from: https://www.leitlinienprogramm-onkologie. de/english-language/.

12 Brouwers MC, Kho ME, Browman GP, Burgers JS, Cluzeau F, Feder G, et al. AGREE II: advancing guideline development, reporting and evaluation in health care. Can Med Assoc J. 2010 Dec 14;182(18):E839-42.

13 Shea BJ, Grimshaw JM, Wells GA, Boers M, Andersson N, Hamel C, et al. Development of AMSTAR: a measurement tool to assess the methodological quality of systematic reviews. BMC Med Res Methodol. 2007 Feb 15;7:10.

14 Higgins JP, Altman DG, Gøtzsche PC, Jüni P, Moher D, Oxman AD, et al. The cochrane collaboration's tool for assessing risk of bias in randomised trials. BMJ. 2011 Oct 18;343: d5928.

15 (SIGN) SIGN. SIGN 50: a guideline developer's handbook. (SIGN publication no. 50). Edinburgh 2015

16 Whiting PF, Rutjes AW, Westwood ME, Mallett S, Deeks JJ, Reitsma JB, et al. QUADAS-2: a revised tool for the quality assessment of diagnostic accuracy studies. Ann Intern Med. 2011 Oct 18;155(8):529-36.

17 Hayden JA, van der Windt DA, Cartwright JL, Côté P, Bombardier C. Assessing bias in stud- ies of prognostic factors. Ann Intern Med. 2013 Feb 19;158(4):280-6.

18 Phillips BBC, Sackett D, Badenoch D, Straus S, Haynes B, Dawes M. The Oxford 2009 levels of evidence. Group ${ }^{\star}$ OLoEW. 2009.

19 Higgins JP, Green S. Cochrane handbook for systematic reviews of interventions. Version 5.1.0 (updated March 2011) [Internet]. 2016 Dec 16. The Cochrane Collaboration. Available from: https://training.cochrane.org/ handbook.

20 Kollmannsberger C, Tandstad T, Bedard PL, Cohn-Cedermark G, Chung PW, Jewett MA, et al. Patterns of relapse in patients with clinical stage I testicular cancer managed with active surveillance. J Clin Oncol. 2015;33(1): 51-7.

21 Daugaard G, Gundgaard MG, Mortensen MS Agerbaek M, Holm NV, Rorth M, et al. Surveillance for stage I nonseminoma testicular cancer: outcomes and long-term follow-up in a population-based cohort. J Clin Oncol. 2014;32(34):3817-23.

22 Oliver RT, Ong J, Shamash J, Ravi R, Nagund V, Harper P, et al. Long-term follow-up of Anglian Germ Cell Cancer Group surveillance versus patients with Stage 1 nonseminoma treated with adjuvant chemotherapy. Urology. 2004;63(3):556-61.

23 Maroto P, Garcia del Muro X, Aparicio J, PazAres L, Arranz JA, Guma J, et al. Multicentre risk-adapted management for stage I nonseminomatous germ cell tumours. Ann Oncol. 2005; 16(12):1915-20.

24 Ondrus D, Kajo K, Stastna V, Ondrusova M. Controversies in the management of clinical stage I nonseminomatous germ cell testicular cancer. Klin Onkol. 2015;28(2):112-5.

25 Albers P, Siener R, Krege S, Schmelz HU, Dieckmann KP, Heidenreich A, et al. Randomized phase III trial comparing retroperitoneal lymph node dissection with one course of bleomycin and etoposide plus cisplatin chemotherapy in the adjuvant treatment of clinical stage I Nonseminomatous testicular germ cell tumors: AUO trial AH 01/94 by the German Testicular Cancer Study Group. J Clin Oncol. 2008;26(18):2966-72.

26 Studer UE, Fey MF, Calderoni A. Adjuvant chemotherapy after orchiectomy in high-risk patients with clinical stage I nonseminomatous testicular cancer. Eur Urol. 1993;23(4): 444-49.

27 Culine S, Theodore C, Terrier-Lacombe MJ, Droz JP. Primary chemotherapy in patients with nonseminomatous germ cell tumors of the testis and biological disease only after orchiectomy. J Urol. 1996;155(4):1296-8.

28 Pont J, Albrecht W, Postner G, Sellner F, Angel K, Holtl W. Adjuvant chemotherapy for high-risk clinical stage I nonseminomatous testicular germ cell cancer: long-term results of a prospective trial. J Clin Oncol. 1996; 14(2):441-8

29 Bohlen D, Borner M, Sonntag RW, Fey MF, Studer UE. Long-term results following adjuvant chemotherapy in patients with clinical stage I testicular nonseminomatous malignant germ cell tumors with high risk factors. J Urol. 1999;161(4):1148-52.

30 Chevreau C, Mazerolles C, Soulie M. Longterm efficacy of two cycles of BEP regimen in high-risk stage I nonseminomatous testicular germ cell tumors with embryonal carcinoma and/or vascular invasion. Eur Urol. 2004;46: 209-14.

31 Bamias A, Aravantinos G, Kastriotis I, Alivizatos G, Anastasiou I, Christodoulou C, et al. Report of the long-term efficacy of two cycles of adjuvant bleomycin/etoposide/cisplatin in patients with stage I testicular nonseminomatous germ-cell tumors (NSGCT): a risk adapted protocol of the Hellenic Cooperative Oncology Group. Urol Oncol. 2011; 29(2):189-93.

32 Tandstad T, Cohn-Cedermark G, Dahl O, Stierner U, Cavallin-Stahl E, Bremnes RM, et al. Long-term follow-up after risk-adapted treatment in clinical stage 1 (CS1) nonseminomatous germ-cell testicular cancer (NSGCT) implementing adjuvant CVB chemotherapy. A SWENOTECA study. Ann Oncol. 2010;21(9):1858-63.

33 Tandstad T, Solberg A, Håkansson U, Stahl O, Haugnes HS, Oldenburg J, et al. Bilateral testicular germ cell tumors in patients treated for clinical stage I non-seminoma within two risk-adapted SWENOTECA protocols. Acta Oncol. 2014;54(4):493-99.

34 Fan G, Zhang L, Yi L, Jiang ZQ, Ke Y, Wang $\mathrm{XS}$, et al. Comparative effectiveness of riskadapted surveillance vs retroperitoneal lymph node dissection in clinical stage I nonseminomatous germ cell testicular cancer: a retrospective follow-up study of 81 patients. Asian Pac J Cancer Prev. 2015;16(8):3267-72.

35 Sturgeon JF, Moore MJ, Kakiashvili DM, Duran I, Anson-Cartwright LC, Berthold DR, et al. Non-risk-adapted surveillance in clinical stage I nonseminomatous germ cell tumors: the Princess Margaret Hospital's experience. Eur Urol. 2011;59(4):556-62. 